\title{
THE EFFECT OF GALVANIC EXERCISE ON DENERVATED AND RE-INNERVATED MUSCLES IN THE RABBIT
}

\author{
BY
}

\author{
E. GUTMANN and L. GUTTMANN
}

(Department of Zoology and Comparative Anatomy, Oxford)

(RECEIVED 22ND OCTOBER, 1943)

IN a previous paper (Gutmann and Guttmann, 1942) it was shown that galvanic exercise of denervated muscles to a great extent counteracted the atrophy of the paralysed muscles and accelerated return to their initial volume after re-innervation. The principle of the method employed was to elicit vigorous contractions but to avoid nociceptive reactions. Stimulation was applied for 20 minutes daily with a current strength of about $5 \mathrm{ma}$.

Recent literature on the effect of electrotherapy is still found to be contradictory. Fischer (1939), Solandt (1942), Solandt et al. (1943) and Hines et al. (1943) have reported favourable results. Eccles (1941) has shown that in disuse atrophy faradic stimulation decreases the weight loss considerably. But negative results have been reported by Chor et al. (1939) and Molander et al. (1941). Chor et al. (1939) even claimed that the beneficial effects of massage and passive movements were lessened rather than augmented by the addition of electrical stimulation. Many clinicians consequently think that the exact value of electrotherapy in treating peripheral nerve injuries has still to be determined (see Newman et al. 1940).

Even among supporters of electrotherapy there is still difference of opinion as to the type of electrical current to be used and as to whether it should be used from the beginning, in the late stages of denervation or after recovery of movement. Moreover many clinicians and experimental workers have only used weak current strength, avoiding any prolonged applications of greater strengths, because of the widely accepted but unproved contention that vigorous contractions and prolonged electrical exercise of denervated muscles may produce additional damage through the excessive fatiguability of denervated muscles.

The experiments which are described in this paper provide further evidences of the beneficial effect of galvanic exercise on denervated and re-innervated muscles. An attempt to find the optimum manner of application, time for starting, duration, and strength of treatment is also described.
In a series of 30 rabbits the muscles treated were those innervated by the peroneal nerve. No attempt was made to use animals of the same age, weight or family. Therefore it is probable that muscles of different animals atrophied at different rates. However, a control was present in each animal in the opposite untreated muscle so that the results to some extent were rendered independent of this variation. The experiments may be divided into two groups. (a) Treatment of denervated muscles without possibility of re-innervation. The peroneal nerve was cut and resected as far as possible on both sides, and the absence of re-innervation of the peripheral stump was confirmed at biopsy. A distinction was made between short-term denervation ( 37 days) and long-term denervation (67-150 days) and in the second group between early and late start of treatment also. (b) Treatment of muscles in which re-innervation was allowed: (1) after crushing the nerve; (2) after division and primary suture of the nerve; (3) after division and secondary suture by cross union. Details of the operative technique will be described later.

Galvanic current only was used in all cases as this type of current is mostly used in man. In all experiments the paralysed muscles of the left leg were exercised while those of the right leg remained untreated. In a single case both sides were treated to compare the effect of different durations of treatment in the same animal. The initial standard method of treatment was 20 minutes galvanic exercise daily at a current strength of 4-6 ma. Copper electrodes of 8 and $3 \mathrm{~mm}$. in diameter covered with gauze and fitted to handles to give a better control were used. Before and during exercise the skin was thoroughly moistened. The anode electrode of $8 \mathrm{~mm}$. diameter was applied at the upper insertion point of the paralysed muscles at the level of the crista tibiæ, but during each daily exercise the point of application was repeatedly altered to avoid local damage to the underlying tissues. The contractions of the muscles were 
elicited by the cathode of $3 \mathrm{~mm}$. in diameter, which was applied to the distal part of the muscles. The application of the cathode was not restricted to one position but it was moved along the muscle belly from the proximal to the distal end. The current was thus directed not only longitudinally through the muscles but also to the various parts of the muscle. The contact with the skin was made very light to avoid local damage and to eliminate any effect due to massage of the muscle. With this current strength of 4-6 ma. vigorous contractions of the individual muscles of the peroneal groups could be elicited without giving rise to nociceptive reactions. Since the skin resistance decreases during the electrical exercise the same vigorous contractions can be obtained by progressively weaker current strength. During 20 minutes of treatment about 500-600 single contractions were obtained. In further experiments the effect of this method was compared with others in which current strength and time of application was modified (see Table I).

The following observations were made during the treatment. (a) At weekly intervals measurements of the circumference of the leg $15 \mathrm{~mm}$. below the crista tibiæ were made with a fine thread. Three separate measurements were made at each examination and the mean value recorded. Though this method is somewhat crude it proved sensitive enough to give some indication of the difference in volume between treated and untreated muscles. It cannot be expected that this method will give a very exact index of the changes in denervated muscles, especially in young animals where growth processes are taking place. But even in such cases an approximate index of the course of volume changes during denervation and re-innervation of the treated and untreated muscles can be obtained. (b) Occasional measurements of the thresholds of the direct excitability of the muscles to faradic current applied through the skin. (c) Time of onset of recovery of motor function, using the spreading reflex of the toes. The amplitude of the spreading was determined, to indicate the difference in the degree of the recovered motor function at the end of treatment between treated and untreated side (Gutmann and Guttmann, 1942).

At the end of treatment a biopsy was made under nembutal anæsthesia and the muscles were exposed on both sides. The following observations were then made. (a) Macroscopical appearance of the muscles. (b) Response of the muscles to stimulation with faradic current. (c) The presence and intensity of fibrillation in the denervated muscles, which could be detected easily by reflecting light from the surface of the exposed muscles. Care was taken to avoid cooling which may abolish fibrillation (see Tower, 1939). (d) Weight of the extirpated muscles (M. tibialis ant. and M. extensor dig.). The muscles were excised at analogous points from the living animal at biopsy, put in a Petri dish with Ringer-soaked gauze and weighed after blotting twice with filter paper. Although the weight of extirpated muscles is generally considered as the standard measurement of muscular atrophy it cannot be regarded as an absolutely satisfactory index, as it measures both the weight of the contractile muscle substance and that of other constituents of the muscle (e.g. connective tissue).

Table I.-Effect of Galvanic Exercise on Muscles allowed to Atrophy without Re-innervation

\begin{tabular}{|c|c|c|c|c|c|c|c|c|c|c|c|}
\hline \multirow{2}{*}{ Rabbit } & \multicolumn{2}{|c|}{$\begin{array}{c}\text { Treatment after } \\
\text { operation } \\
\text { (days) }\end{array}$} & \multirow{2}{*}{$\begin{array}{c}\text { Duration of } \\
\text { daily } \\
\text { treatment } \\
\text { (minutes) }\end{array}$} & \multirow{2}{*}{$\begin{array}{l}\text { Current } \\
\text { strength } \\
\text { (ma.) }\end{array}$} & \multicolumn{2}{|c|}{$\begin{array}{l}\text { Weights of } \\
\text { M. tibialis ant. } \\
\text { (gm.) }\end{array}$} & \multirow{2}{*}{$\begin{array}{c}\text { Weight } \\
\text { of } \\
\text { treated } \\
\text { in per } \\
\text { cent. of } \\
\text { untreated }\end{array}$} & \multicolumn{2}{|c|}{$\begin{array}{c}\text { Circumference } \\
\text { of leg } \\
\text { (mm.) }\end{array}$} & \multicolumn{2}{|c|}{$\begin{array}{c}\text { Mean diameter } \\
\text { of muscle } \\
\text { fibres }(\mu)\end{array}$} \\
\hline & start & $\begin{array}{c}\text { dura- } \\
\text { tion }\end{array}$ & & & treated & $\underset{\text { treated }}{\text { un- }}$ & & treated & $\underset{\text { treated }}{\text { un- }}$ & treated & un- \\
\hline $\begin{array}{r}679 \\
971 \\
992 \\
1005 \\
892 \\
893 \\
1017\end{array}$ & $\begin{array}{l}7 \\
7 \\
7 \\
7 \\
7 \\
7 \\
7\end{array}$ & $\begin{array}{l}30 \\
30 \\
30 \\
30 \\
30 \\
30 \\
30\end{array}$ & $\begin{array}{c}20 \\
20 \\
20 \\
20 \\
10 \\
30 \\
20 \text { (twice } \\
\text { weeklv) }\end{array}$ & $\begin{array}{l}5 \\
5 \\
5 \\
5 \\
5 \\
5 \\
5\end{array}$ & $\begin{array}{l}2.28 \\
1.58 \\
1.54 \\
2.20 \\
1.97 \\
2.68 \\
1.46\end{array}$ & $\begin{array}{l}1.45 \\
0.89 \\
0.87 \\
1.56 \\
1.49 \\
1.60 \\
1.36\end{array}$ & $\begin{array}{l}157 \\
177 \\
177 \\
141 \\
132 \\
167 \\
107\end{array}$ & $\begin{array}{l}85 \\
79 \\
75 \\
82 \\
73 \\
73\end{array}$ & $\begin{array}{l}78 \\
75 \\
71 \\
79 \\
71 \\
70\end{array}$ & $\begin{array}{l}\overline{22} \\
26 \\
-24 \\
31 \\
25\end{array}$ & $\begin{array}{l}-16 \\
20 \\
20 \\
23 \\
23\end{array}$ \\
\hline 983 & 7 & 30 & $\begin{array}{l}20 \text { (twice } \\
\text { weekly) }\end{array}$ & 5 & 0.80 & 0.66 & 121 & 73 & 71 & 19 & 17 \\
\hline 981 & 7 & 30 & 15 contrac- & 5 & 0.86 & 0.79 & 109 & 67 & 67 & 22 & 20 \\
\hline $\begin{array}{c}1016 \\
956 *\end{array}$ & $\begin{array}{l}7 \\
7\end{array}$ & $\begin{array}{l}30 \\
30\end{array}$ & $\begin{array}{c}20 \\
30 \text { (left) }\end{array}$ & $\frac{0 \cdot 5-1}{5}$ & $\begin{array}{l}1.47 \\
1.95\end{array}$ & $\begin{array}{l}1.20 \\
1.78\end{array}$ & $\begin{array}{l}122 \\
109\end{array}$ & $\begin{array}{l}77 \\
83\end{array}$ & $\begin{array}{l}75 \\
80\end{array}$ & $\begin{array}{l}23 \\
26\end{array}$ & $\begin{array}{l}20 \\
21\end{array}$ \\
\hline $\begin{array}{l}957 \\
970 \\
895 \\
909\end{array}$ & $\begin{array}{r}7 \\
7 \\
90 \\
90\end{array}$ & $\begin{array}{l}60 \\
90 \\
60 \\
60\end{array}$ & $\begin{array}{l}20 \\
20 \\
20 \\
20\end{array}$ & $\begin{array}{l}5 \\
5 \\
5 \\
5\end{array}$ & $\begin{array}{l}2 \cdot 37 \\
2 \cdot 47 \\
1.07 \\
1 \cdot 34\end{array}$ & $\begin{array}{l}1.30 \\
1.53 \\
0.95 \\
1.06\end{array}$ & $\begin{array}{l}182 \\
161 \\
113 \\
126\end{array}$ & $\begin{array}{l}79 \\
81 \\
78 \\
79\end{array}$ & $\begin{array}{l}74 \\
73 \\
77 \\
77\end{array}$ & $\begin{array}{l}29 \\
29 \\
18 \\
23\end{array}$ & $\begin{array}{l}20 \\
20 \\
16 \\
19\end{array}$ \\
\hline
\end{tabular}

* Animal in which the left side (see under " treated ") was treated for 30, the right side (see under " untreated ") for 10 minutes. 
(e) Histological study of the treated and untreated muscles. The muscles were fixed in Bouin's fluid and frozen sections were cut and stained with the van Giesen technique. The atrophy in the treated and untreated muscles was compared quantitatively by finding the mean diameter of a sample of muscle fibres. The measurements were done with a micrometer eye-piece and the samples were taken from the longest diameter of the section, 200 fibres being measured in each muscle. Starting at the edge of the preparation a group of 20 contiguous fibres was measured. The scale of the micrometer eye-piece was then moved on a distance equal to $\frac{1}{10}$ of the diameter of the whole section and 20 more fibres measured and so on across the muscle. This method gives a near approach to a random sampling, though perhaps there is a tendency to omit measurements of very small fibres. It provides a means of measuring representative and corresponding samples of each muscle.

\section{Results}

The effect of galvanic exercise on denervated muscles without re-innervation.

\section{Short-term denervation}

In Table I the first 11 animals are cases with shortterm denervation (37 days). In all these animals galvanic exercise started at the 7 th day following denervation and was continued for 30 days. In some of these cases current strength and time of daily application of treatment was modified (see later). The 7 th day was found suitable for an early start of treatment. During the days immediately after operation the skin over the anterolateral aspect of the leg is often œdematous and easily becomes inflamed. In all cases except those in which the muscles were either treated with weak current strength (animal 1016) or for a short time only (983, 1017, and 981), the beneficial effect of the galvanic exercise was obvious in every respect. The treated muscles kept a good contractile power contrasting with the slow and sluggish contraction of the untreated muscles to direct stimulation. In all cases there was a lower threshold of direct excitability of the muscles on the treated side (see Gutmann and Guttmann, 1942). Of interest was the observation that, during the galvanic exercise a vasodilatation with an increase in the volume of the treated muscles developed 4-7 minutes after beginning of treatment.

At the end of treatment the circumference and weight were found in all cases to be greater in the treated than in the untreated muscles (see Table I). At biopsy the macroscopical appearance of the treated muscles was healthy and hardly differed from that of the normal muscles. In most of the cases the pallor of the untreated muscles contrasted strikingly with the red colour of the treated muscles. Both treated and untreated muscles showed fibrillation. The histological examination revealed less severe atrophy after treatment, the mean diameter of the muscle fibres being in all cases greater in the treated muscles, while the epi-, peri- and endomysium were all thinner in the treated muscles than in the untreated.

\section{Long-term denervation}

Four animals were left denervated for longer periods (67-150 days). The animals were treated 20 minutes daily with a current strength of $5 \mathrm{ma}$. to allow comparison of the effect of early and late commencement of treatment. The result is strikingly in favour of early commencement of treatment (see Table I). In two cases $(957,970)$ the treatment was started 7 days after denervation, the period of denervation being 67 and 97 days. The effect of treatment was very marked in both cases, showing that the treatment is able to retard the rate of atrophy effectively through longer times of denervation. Measurements of circumference enabled us to follow approximately the successive changes in treated and untreated denervated muscles over longer periods (see Fig. 1). It appears from this

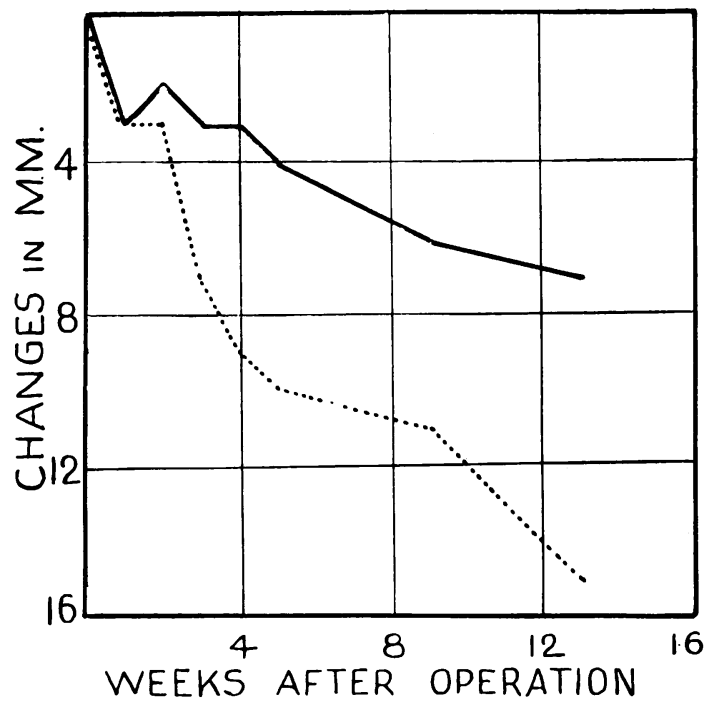

FIG. 1.-Changes in the circumference of the legs, measured by cotton thread, of rabbit 970 , in which the peroneal nerve was resected on both sides. Galvanic exercise of the left leg (full line) was begun 7 days after operation and was continued for 90 days.

that the main effect of treatment is achieved in the first month. As the rate of atrophy is quicker during this initial period this is to be expected. In both animals a good contractile power of the denervated muscles was preserved throughout the whole treatment. Clear differences were also revealed by the macroscopical and histological appearance of the exposed muscles (see Figs. 2 and 3). The degree of atrophy was not the same in all parts of the muscle. The effect of treatment was especially marked in the outer parts of the muscle, where there was no increase in connective tissue and where the muscle fibres seemed to have escaped the effect of denervation almost completely. 


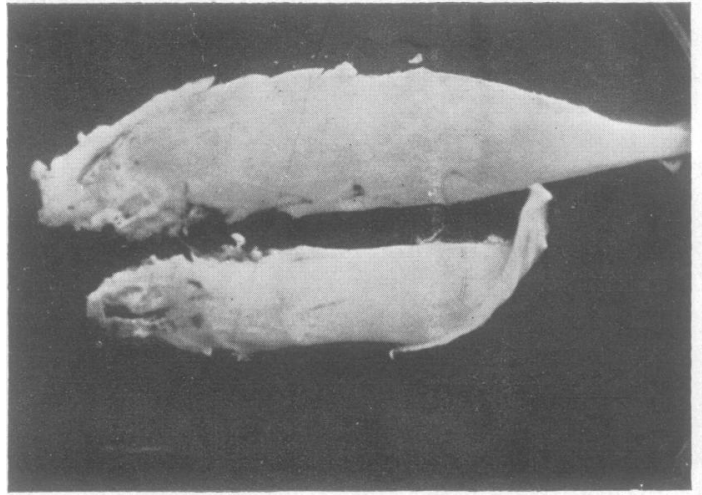

(a)

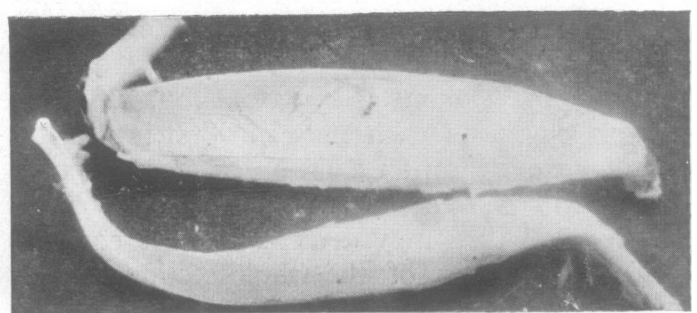

(b)

FIG. 2.-Tibialis anterior muscles $(a)$ and Extensor digitorum muscles $(b)$ of the treated and untreated legs of rabbit 957. Galvanic exercise of the left leg was begun 7 days after operation and was continued for 60 days.

In contrast to these two cases the effect of galvanic exercise was definitely less conspicuous in the cases with late start of treatment $(895,909)$. The treatment was started 90 days after denervation and continued for 60 days. At the beginning the muscles on both sides showed advanced atrophy, their circumferences being square. At first the muscles of the treated side showed the same sluggish and weak responses to galvanic stimulation as those of the untreated side. There was also a considerable fatigue to repeated stimuli, so that after an exercise of 3-5 minutes the muscles ceased to react altogether, and only contractions of the normal muscles of the tibial group were obtained. The treatment was, however, continued daily, the exercise being gradually increased in current strength and duration. After about 10 days an exercise of 20 minutes became possible and the muscle contraction became brisker and there was less sign of fatigue. At the end of treatment the difference in circumference and weight was much less than in the animals with early start of treatment, but the histological examination revealed some difference in favour of the treated muscles (see Fig. 4). The muscles were heavier and the muscle fibres larger and there was less connective tissue on the treated side (see Table I).

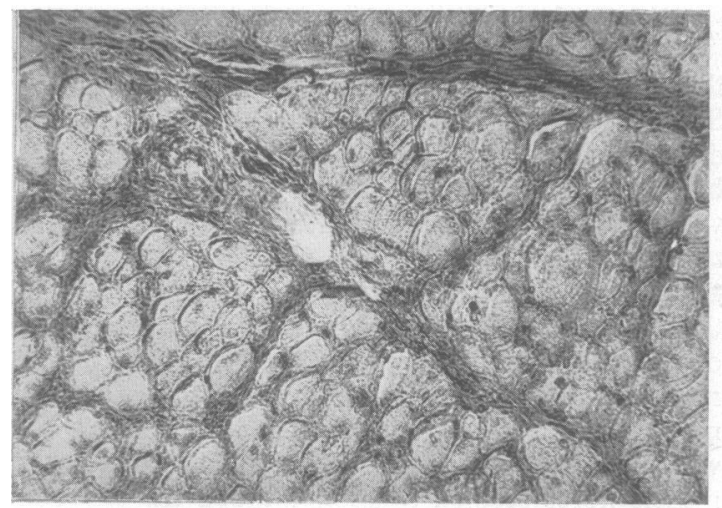

(a)
3. Evaluation of various modes of treatment (With special reference to minimal and maximal treatment)

As mentioned before, in several cases various modifications of the standard technique were employed (Table I). In animal 981 only 15 contractions were elicited daily. This method had been used by Chor et al. (1939). In two other animals the duration of the daily exercise was 10 minutes (892) and 30 minutes (15 minutes twice daily) (893) respectively. The current strength was unchanged. As shown in Table I good results can be obtained by 10 minutes' treatment only, provided sufficient current strength is used to elicit vigorous contractions of the denervated muscles. The results which were obtained in the animals treated for 20 minutes and in that (893) treated for 30 minutes daily did, however, seem better. The superiority of the longer treatment, although not very marked, can be seen in animal 956 in which the left side was treated for 30 , and the right side for 10 minutes only. In two animals $(983,1017)$ a treatment of 20 minutes duration was given twice weekly. This exercise proved ineffective as compared with the daily exercise of 30,20 or even 10 minutes duration. In a further experiment (1016) the duration of 20

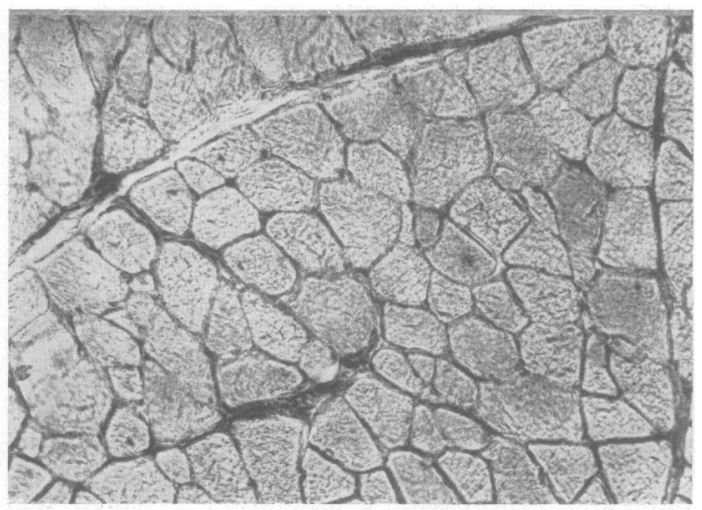

(b)

FIG. 3.-Cross-sections of untreated $(a)$ and treated $(b)$ muscles of rabbit 957. 
Table II.-Comparison of Muscles given Maximum Treatment with Normal and Atrophic Muscles

\begin{tabular}{lll|c|c|c|c|c|c}
\hline \multicolumn{2}{c|}{ Rabbit } & & $\begin{array}{c}\text { Period of } \\
\text { denervation } \\
\text { (days) }\end{array}$ & $\begin{array}{c}\text { Weight of M. tibialis ant. } \\
\text { (gm.) }\end{array}$ & $\begin{array}{c}\text { Weight of } \\
\text { denervated } \\
\text { muscle as } \\
\text { per cent. of } \\
\text { normal }\end{array}$ & $\begin{array}{c}\text { Mean diameter of muscle } \\
\text { fibres }(\mu)\end{array}$ \\
\hline 934 (denervated, treated) & $\ldots$ & 60 & 2.65 & 2.20 & 83 & 38 & 32 \\
761 (denervated) &.. & $\ldots$ & 60 & 2.48 & 1.02 & 41 & 36 & 17 \\
856 (denervated) & $\ldots$ & $\ldots$ & 60 & 2.08 & 0.88 & 42 & 36 & 19 \\
\hline
\end{tabular}

minutes was unchanged but the current strength was reduced to about 1 ma., a current strength which elicited very weak and just visible action of the muscles in the rabbit, the method used by Molander et al. (1942). This treatment also had a negligible effect.

Comparison of treated and untreated denervated muscles alone does not allow us to determine to what extent atrophy can be prevented, or particularly whether it can be completely prevented by galvanic exercise. This can only be decided by comparison of treated denervated with the normal muscle of the opposite side. In animal 934 (see Table II) the peroneal nerve was resected on one side only. A maximal treatment lasting for one hour daily (30 minutes twice daily) was started immediately after denervation and was continued for 2 months. No attempt was made to avoid fatiguing of the exercised muscles. As a control the same operation was performed in two further animals but without treating the denervated muscles. As shown in Table II the weight loss of the treated denervated muscle (934) was only 17 per cent. compared with 59 and 58 per cent. weight loss in the denervated untreated muscles (animals 761 and 856). Similar relations are shown when the mean diameters of the muscle fibres in the treated denervated, untreated denervated and normal muscles are compared (see Table II).

The histological conditions of the muscles of animals 934 and 856 are shown in Fig. $5 a, b, c$, and $d$. As already noted the histological picture in a treated denervated muscle is not the same in all parts of the muscle. Differences in the rate of atrophy between different parts of the muscle can be found in untreated denervated muscles, larger muscle fibres being found in the more peripheral parts. The difference is especially marked in denervated treated muscles, and evidently there is a greater effect upon the muscle fibres which lie close to the electrodes. In the maximally treated muscle the outer parts (see Fig. $5 b$ ) show an almost normal appearance (Fig. 5a) but in the inner parts the atrophy has not been so effectively prevented (Fig. 5c), but no part of the treated muscle shows the same advanced degree of atrophic changes as the denervated one (see Fig. 5d). This observation applied not only to the size of the muscle fibres but particularly to the increase in connective tissue (compare $5 d$ and $5 c$ ).

The differences in fibre size and fibre size distribution of treated denervated, untreated denervated and normal muscles are shown in the histograms of Fig. 6. The upper diagram of Fig. $6 a$ relating to animal 934 shows the distribution of fibre diameters in the muscle of the normal side (mean diameter $38 \mu$ ), the lower that of the maximal treated denervated muscle (mean diameter $32 \mu$ ). This latter histogram shows the skewed distribution of fibre diameters which seems to be characteristic of denervated muscles.

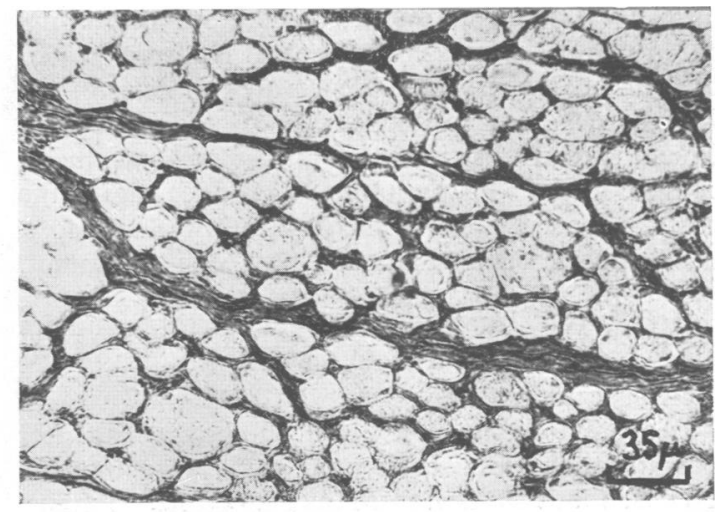

(b)

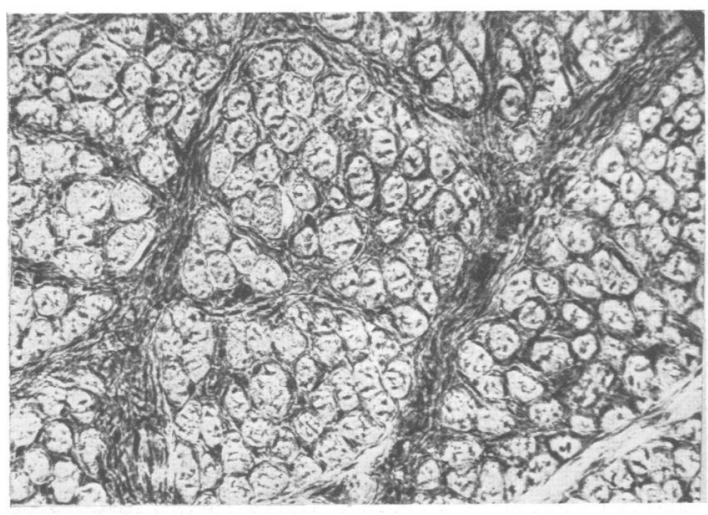

(a)

FIG. 4.-Cross-sections of untreated $(a)$ and treated $(b)$ muscles of rabbit 909 . Treatment was begun 3 months after operation and was continued for 60 days. 


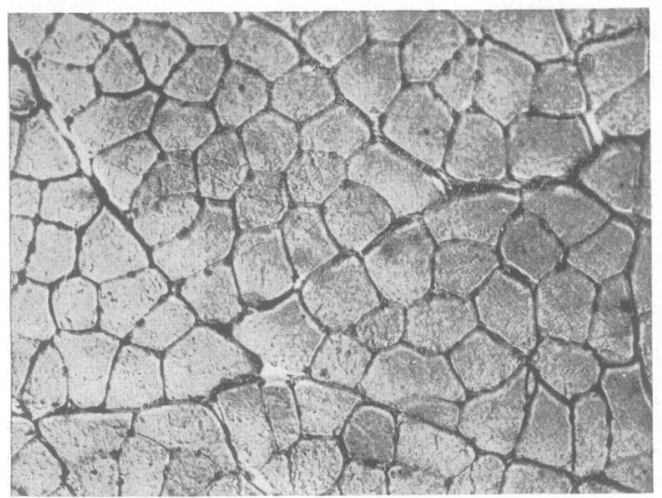

(a)

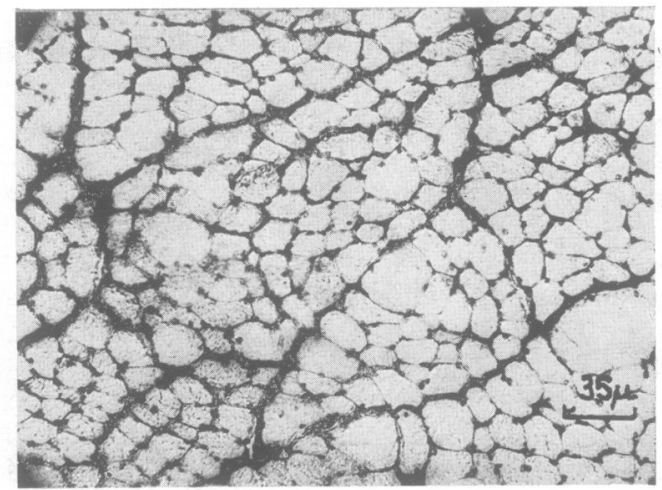

(c)

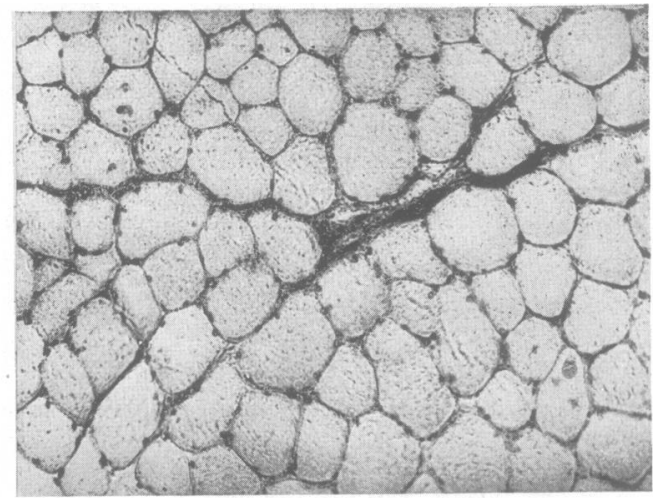

(b)

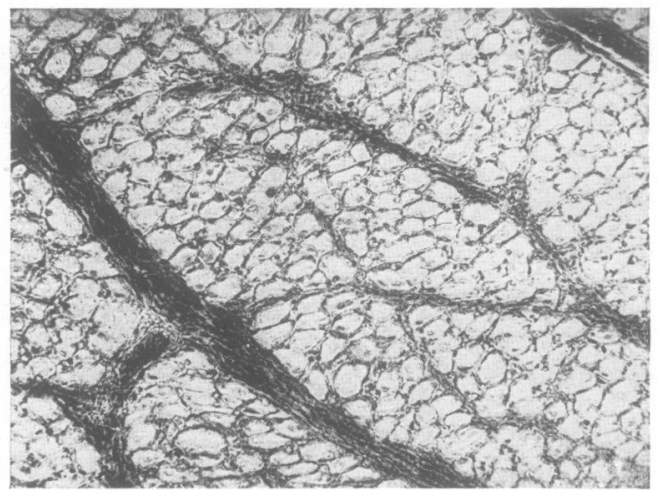

(d)

FIG. 5.-Cross-sections of M. tibialis anterior $(a)$ of the normal control side, $(b)$ peripheral part of muscle given maximal treatment, $(c)$ central part of muscle given maximal treatment (animal 934), $(d)$ untreated muscle denervated for the same time as (b) (animal 856) and (c).

Fig. $6 b$ shows the histogram of animal 856 . The upper diagram shows the distribution of the fibre diameters of the normal muscle (mean diameter $36 \mu$ ), the lower that of the untreated denervated muscle (mean diameter $17 \mu$ ). Comparing the histograms of animal 934 and 856 it appears that the mean diameter has shifted much more towards the smaller values in the denervated untreated, and that there are more large fibres in the treated denervated muscle. Fig. $6 c$ shows the histogram of animal 970 in which the muscles of the left leg were treated for 3 months whereas the denervated muscles of the right side remained untreated. Both histograms show a skewed distribution, but the mean diameter is higher and the histogram has a broader base in the treated denervated muscle, indicating that more muscle fibres of large diameter have been kept intact.

\section{The effect of galvanic exercise on denervated muscles with nerve repair}

\section{After crushing}

In a previous paper it has been shown that after crushing the peroneal nerve with fine watchmaker's forceps, about $80 \mathrm{~mm}$. from the $\mathrm{M}$. peroneus longus, 20 minutes daily treatment with a current strength of about $5 \mathrm{ma}$. produced no significant difference in the time of onset of motor recovery (Gutmann and
Guttmann, 1942). The data from these animals are given in Table III for comparison. The difference in muscle weight was clear in all cases. In animal 390 (see Table III) treatment was continued for 85 days after the first reappearance of motor function. The final differences in weight and circumference between treated and untreated muscles were not great, but where biopsy was performed shortly after motor recovery the differences in muscle weight and circumference (Fig. 7) were found to be much greater.

It appears therefore that the differences between treated and untreated muscles are partly equalized in the months following recovery. Muscles regain their initial weight after crushing about 3 months after recovery, even when no treatment is applied (E. Gutmann, 1942). It must be remembered, however, that crushing at a single point at a relatively short distance from the muscle gives ideal conditions for the re-innervation. Reflex response of the muscle begins after about 40 days and therefore atrophic changes never become severe.

\section{After primary suture}

After cutting the peroneal nerve in the middle of the thigh the primary or secondary suture was made by the fibrin method of Young and Medawar (1940). In the first 4 cases of primary suture the galvanic 


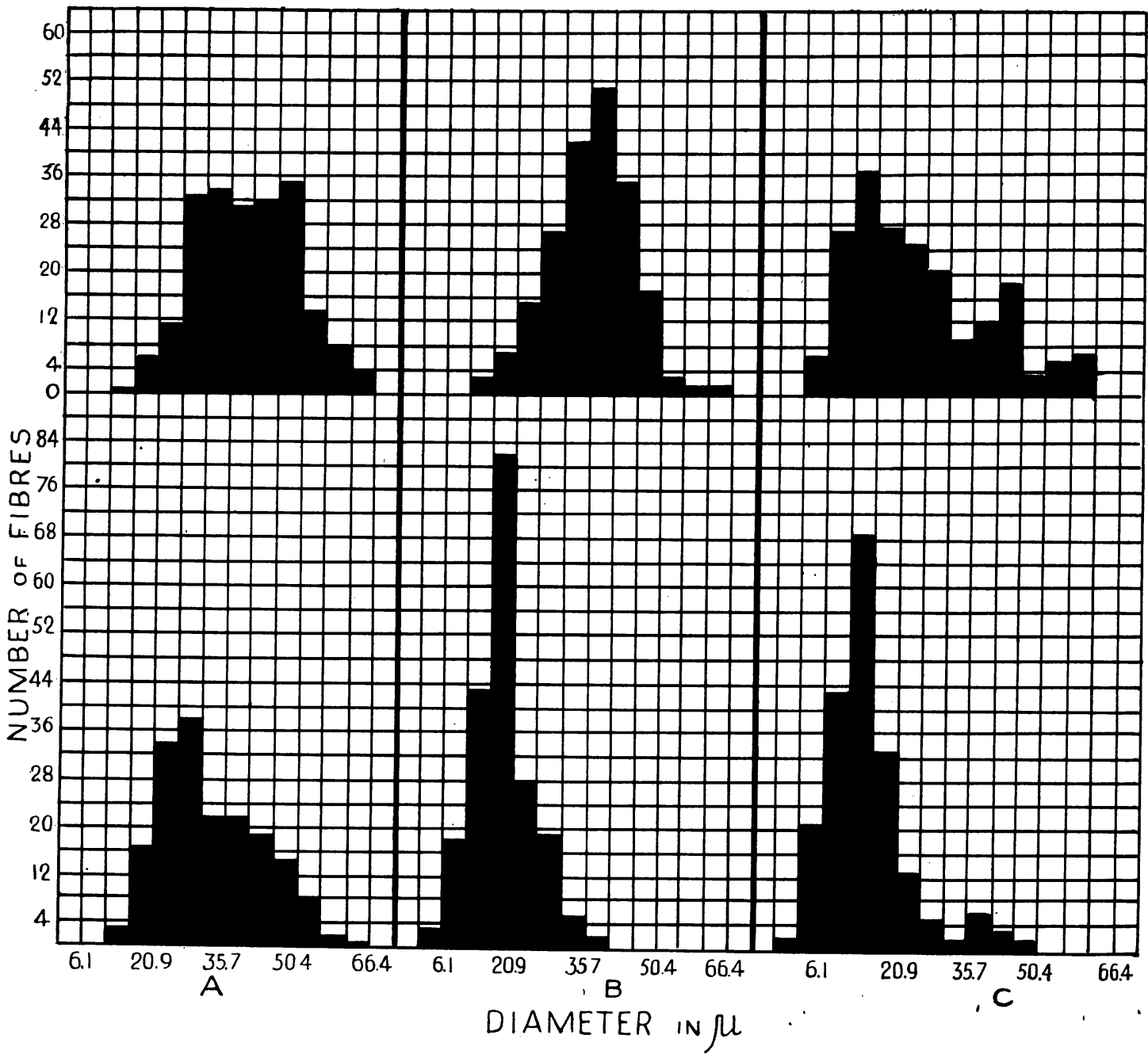

FIG. 6.-Histogram showing the spectrum of fibre diameters in normal, denervated treated and denervated untreated muscles. (a) Animal 934-normal (upper diagram) and treated (lower diagram) side. (b) Animal 856-normal (upper diagram) and denervated untreated (lower diagram) side. (c) Animal 970-treated denervated (upper diagram) and denervated untreated (lower diagram) side. For further details see text.

Table III.-EFfect of Galvanic EXercise on Muscles allowed to become Re-INNervated

\begin{tabular}{|c|c|c|c|c|c|c|c|c|}
\hline \multirow{2}{*}{ Rabbit } & $\begin{array}{c}\text { Treatment after } \\
\text { operation }\end{array}$ & \multicolumn{2}{|c|}{$\begin{array}{c}\text { Time of recovery } \\
\text { (days) }\end{array}$} & \multicolumn{2}{|c|}{$\begin{array}{l}\text { Weights of } \mathbf{M} \text {. } \\
\text { tibialis ant. (gm.) }\end{array}$} & \multirow{2}{*}{$\begin{array}{c}\text { Weight of } \\
\text { treated in per } \\
\text { cent. of un- } \\
\text { treated muscle }\end{array}$} & \multicolumn{2}{|c|}{$\begin{array}{c}\text { Circumference of } \\
\text { leg (mm.) }\end{array}$} \\
\hline & duration & treated & untreated & treated & untreated & & treated & untreated \\
\hline
\end{tabular}

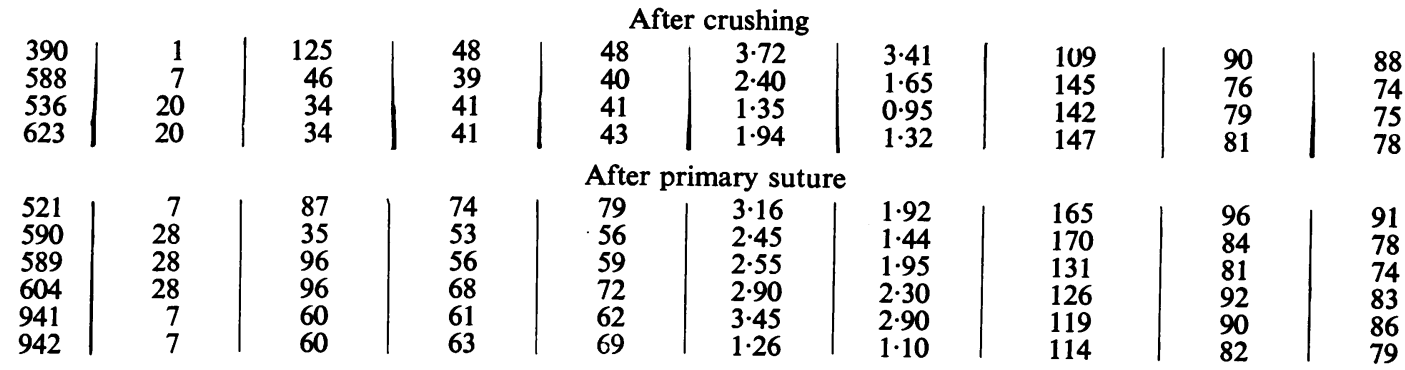

After secondary suture (cross union)

\begin{tabular}{l|l|l|l|l|l|l|l|l|l|l}
512 & 7 & 107 & - & - & 0.82 & 0.60 & 137 & 68 & 67 \\
606 & 7 & 128 & - & - & 2.22 & 0.98 & 227 & 67 & 59 \\
605 & 67 & 68 & - & - & 0.90 & 0.75 & 120 & 59 & 54 \\
\hline
\end{tabular}

In all cases, except 941 and 942, treatment was continued until biopsy. In these two animals treatment was interrupted at the first appearance of motor function. Biopsy was then performed 4 months later. 

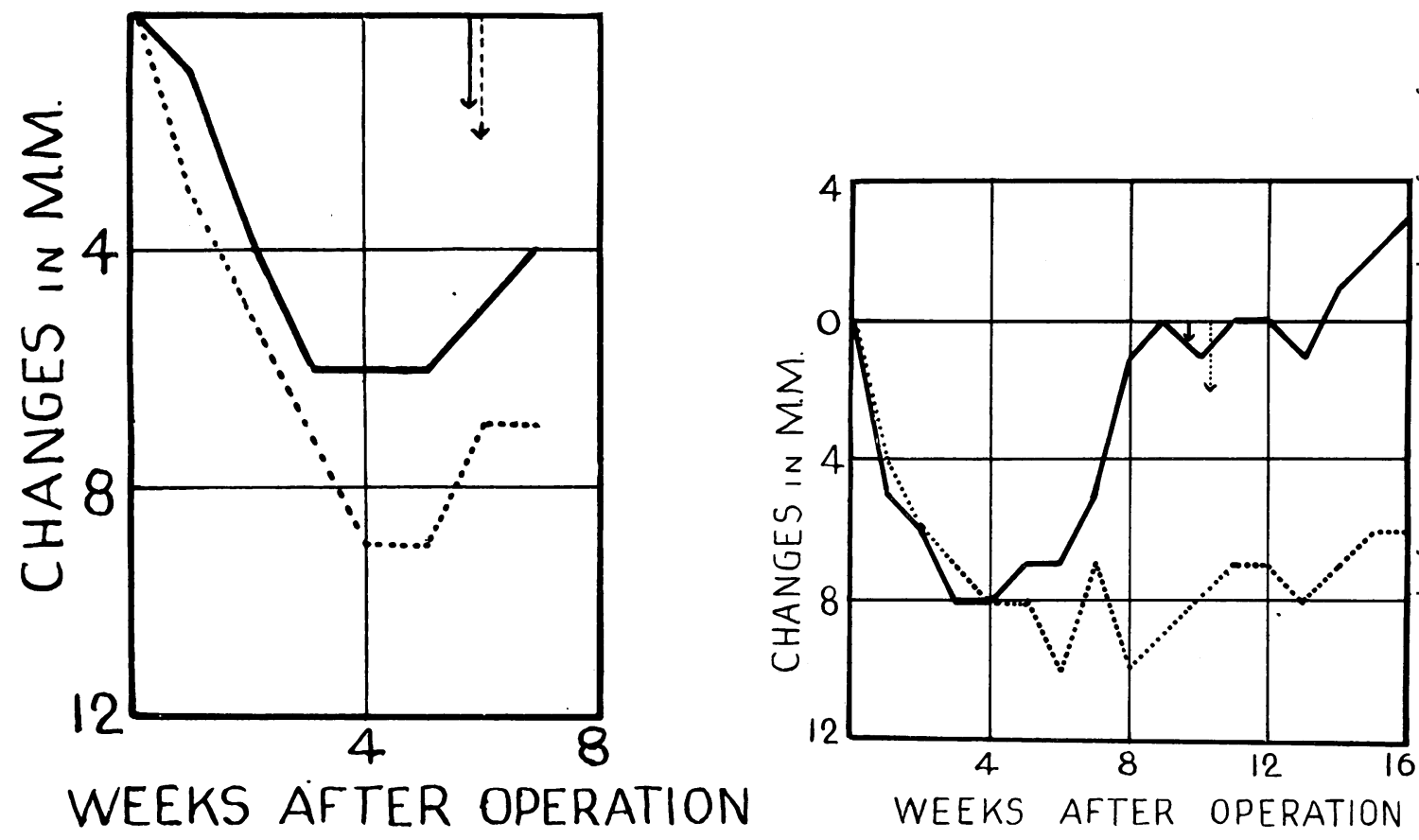

Fig. 7.-Changes in the circumference of the legs, measured by cotton thread, of rabbit 588 in which the peroneal nerve was crushed on both sides. Galvanic exercise was begun 7 days after operation and was continued to the end of the experiment. Treated leg (full line), untreated leg (dotted line). The vertical arrows indicate the times of onset of functional recovery.

exercise was continued beyond the time of motor recovery until biopsy, which was performed 7,15 , 52 , and 65 days after the first reflex movement appeared (see Table III). Comparing the animals 590,589 , and 604 , in all of which treatment was started 28 days after operation, the effect of treatment is more conspicuous in animal 590 in which the biopsy was performed 7 days after onset of motor recovery than in animals 589 and 604 in which biopsy was performed at a later date ( 52 and 65 days after motor recovery). The initial differences resulting from treatment are equalized after recovery, but less completely than in the quick recovery after crushing the nerve. The measurements of circumference in animal 604 show that on the treated side the muscles regain their initial volume much more quickly than on the untreated side (Fig. 8).

Recovery of motor function was observed slightly earlier on the treated side, but the difference was small and probably not significant. But in all cases the spreading of the toes regained greater amplitude on the treated side.

The question arises to what extent the differences in weight are maintained in the treated muscles after interruption of the treatment. In 2 animals (941 and 942) treatment was started 7 days after operation and continued until the time of motor recovery. The treatment was then interrupted and the muscles examined by biopsy 4 months later. The effects of the therapy are certainly equalized to some extent during recovery (see Table III) but clear differences

FIG. 8.-Changes in circumference of the legs, measured by cotton thread, of rabbit 604 , in which the peroneal nerve was cut and sutured on both sides. Galvanic exercise was begun 28 days after operation and was continued to the end of the experiment. Treated leg (full line), untreated leg (dotted line). The vertical arrows indicate the times of onset of functional recovery.

still remain. Histological examination reveals that the muscle fibres are larger on the treated side, the mean diameter of the muscle fibres in animal 942 being $35 \mu$ on the treated and $30 \mu$ on the untreated side. Moreover there is less connective tissue in the muscles of the treated side.

\section{After secondary suture by cross union}

To obtain longer times of denervation secondary sutures by cross unions have been used. This method allows delayed suturing of a nerve but has the disadvantage of producing defective function and of the difficulty in estimating the onset and degree of motor recovery exactly. It is, therefore, difficult to estimate the degree to which muscles have recovered after re-innervation, but the experiments provide further evidence of the effect of therapy on muscles which have been re-innervated after prolonged periods of denervation. At an initial operation the peroneal nerve was cut and resected on both sides. Two months later a second operation was performed in which the tibial as central stump was sutured into the peripheral stump of the peroneal nerve. Treatment of the left side started either 7 days after the first (animal 606) or second operation (animal 605) and was continued about 2 months after the second operation, at which time a biopsy was performed. It can be seen that the differences in weight and circumference are definitely more conspicuous in the case 606 in which treatment 


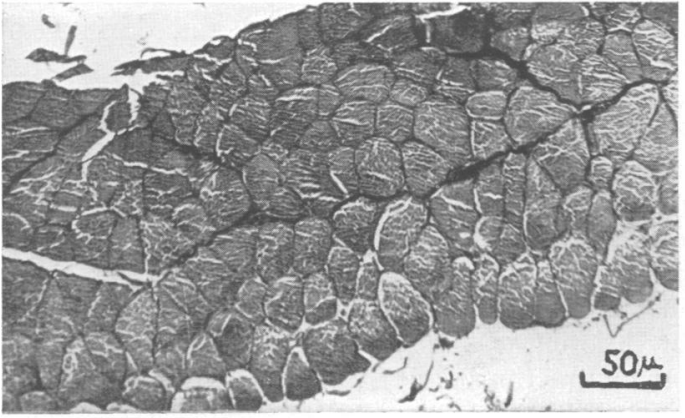

(a)

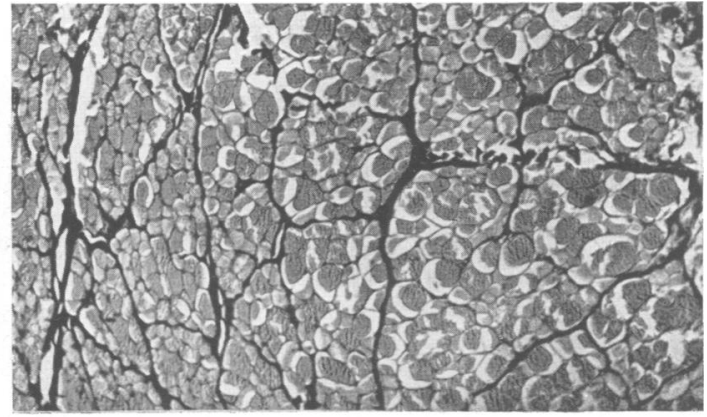

(b)

FIG. 9.-Cross-section of treated $(a)$ and untreated $(b)$ muscles of rabbit 606 , in which the peroneal nerve was resected at an initial operation and sutured with the tibial as central stump at a second operation 2 months later. Galvanic exercise of the left leg (full line) began 7 days after the first operation and was continued to the end of the experiment.

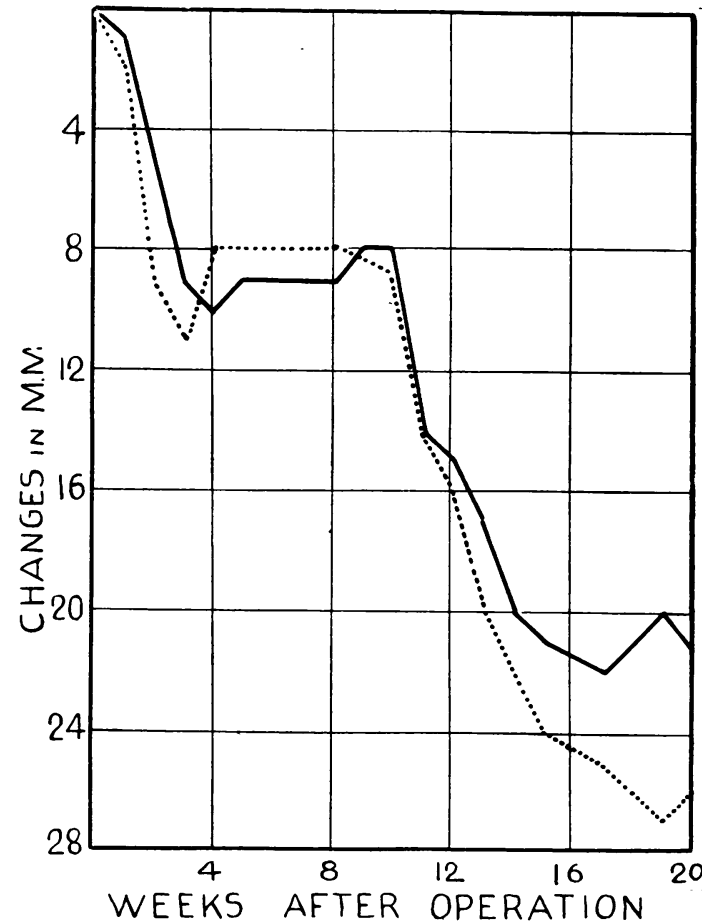

FIG. 10.-Changes in the circumference of the legs, measured by cotton thread, of rabbit 605 , in which the peroneal nerve was resected at an initial operation and sutured with the tibial as central stump at a second operation 2 months later. Galvanic exercise of the left leg (full line) began 7 days after the second operation and was continued to the end of the experiment.

was continued throughout the whole period of denervation.

Fig. 9 shows a cross-section of the treated and untreated muscle in animal 606. The muscle fibres are larger and there is less connective tissue on the treated side. Figs. 10 and 11 show the results of measurement of the circumferences in animal 605 and 606. In animal 606 the degree of $x:-3 p h y$ is considerably less, while recovery of mus $\mathrm{z} 2 \mathrm{z}$ volume proceeds more quickly after re-innervation.

Animal 512 of the same series is of special interest for treatment was also started on it 7 days after the

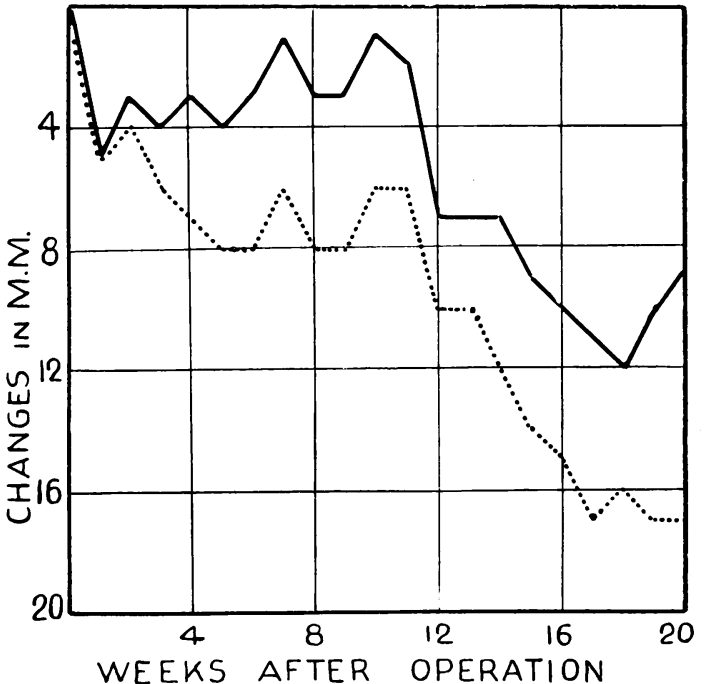

FIG. 11.-Changes in the circumference of legs, measured by cotton thread, of rabbit 606 , in which the peroneal nerve was resected at an initial operation and sutured with the tibial as central stump 2 months later. Galvanic exercise of the left leg (full line) began 7 days after the first operation and was continued to the end of the experiment.

first operation. After the second operation in which the cross union was performed the animal fell ill and lost heavily in weight, became extremely emaciated and died two weeks before the planned treatment was finished. As shown in Table III the effect of treatment was much less marked compared with animal 606 in which the identical experiment was made. The poor general state of the animal 512 was apparently the reason for the relatively slight effect of the galvanic exercise.

\section{Discussion}

The results of all these experiments show clearly that the effect of galvanic exercise varies with its time and duration of application. The effect in preventing atrophy was found to be especially marked after daily application, with a current strength sufficient to elicit vigorous contractions of the muscles. The effect was greater the earlier the 
treatment was started. Twenty minutes galvanic exercise gave very satisfactory results and has been used as the standard time of application, but 10 minutes daily exercise gave results only slightly inferior, while 30 minutes exercise showed little superiority to 20 minutes. No damage of denervated muscles was detected by the longer duration of daily treatment. It may be remembered that even in animal 934 in which no attempt was made to avoid fatiguing the denervated muscles a very satisfactory result was obtained. These findings, which agree with those of Fischer (1939) and Hines, et al. (1943) do not support the view held by many physiologists and clinicians that galvanic exercise of paralysed muscles should not be used during the period of denervation, especially in the early stages. In fact no harmful effect of fatigue on denervated muscles of the rabbit was found and the results indicate that fatigue of denervated muscles by galvanic exercise in man may not be so harmful as formerly thought.

The main effect of treatment was seen during the period of denervation. But even when the muscles were followed into the later stages of recovery the differences between treated and untreated muscles were still clear, though less marked. The treated muscles were found to be in a better state even 4 months after the galvanic exercise had been discontinued (animals 941 and 942).

After re-innervation of a muscle its "trophic state" will be restored spontaneously to a greater or less degree by voluntary impulses. Although there cannot be any doubt that in man active exercise by voluntary impulses is the best treatment for a recovering muscle, it must be remembered that at the time of motor recovery muscle atrophy is still very marked and the power of voluntary or reflex movement is limited. Moreover, longer times of denervation and less successful re-innervation can be expected in most of the human cases. It is, therefore, advisable to continue electrical exercise until motor recovery is satisfactory, for as clinical experience has shown electrotherapy is most useful in augmenting active exercise in cases in which the patient co-operates poorly although re-innervation of the muscles is taking place (Guttmann L., 1942).

It is still an unsettled question whether during the periods of denervation and re-innervation other forms of electrical current (sinusoidal, faradic) may be preferable to galvanic current in man as well as in animals. It must be remembered that in most human cases re-innervated as well as denervated muscles do not respond to faradic stimuli at the beginning of functional recovery, so that any treatment with faradism of such muscles is useless. Recently Solandt et al. (1943) found in rats that a sinusoidal current of low frequency ( 25 cycles) was more effective than other forms (galvanic, faradic and sinusoidal current of 60 cycles). These interesting experiments . were concerned only with the first period of denervation (11 days treatment after denervation) and it still remains to be seen whether the treatment employed will prove more effective in the later stages of denervation and during early stages of recovery, and whether the current used will cause less irritation of sensory fibres and so be better tolerated. These authors also found that the effectiveness increases with the number of treatments daily but that no differences are obtained by varying the length of treatment within the limits employed (1-5 minutes). In the present experiments, however, it was found that treatment had no or little effect when applied for a short time only (15 contractions daily).

The demonstration of the beneficial effect of galvanic exercise on denervated muscles has an important bearing on the problem of the cause of denervation atrophy which is still the subject of controversy. The theory of Langley and Kato (1915) that atrophy of denervated muscles is a fatigue phenomenon caused by ceaseless fibrillation was widely accepted until quite recently (Tower, 1937). The negative experimental results of Langley and Kato on electrotherapy and their statement that " the fact that the denervated muscles are in a state of continuous fibrillation makes it a priori an open question whether further activity caused by electrical stimulation will be beneficial" seems to have influenced many clinicians to condemn galvanic exercise. In spite of the beneficial effect of galvanic exercise described in the present experiments all the treated muscles were found to be still fibrillating, even those given maximum treatment and showing little atrophy. No significant difference in the intensity of fibrillation between treated and untreated muscles was observed at visual inspection. Fibrillation definitely follows denervation but there is no proof that it is the immediate cause of atrophy. In recent years this problem has been repeatedly discussed and although it is still unsettled some results suggest a relative independence of atrophy and fibrillation. Solandt and Magladery (1940) found in rats that quinidin reduces or abolishes fibrillation without greatly affecting atrophy. Weddell, et al. (1943) found no correlation in electromyographic studies between the degree of fibrillation and the rapidity of muscle atrophy.

Most of the negative results of electrotherapy have been due to inadequate technique. The effect of the condensor discharges used by Langley and Kato (1915) was very small and they stated " either then the daily induced contractions were insufficient in number to replace the normal contractions or the change in the muscles is not simply an inactivity atrophy." In fact, comparison of intensive with insufficient treatment, described here, indicates that the first explanation of Langley and Kato is the correct one (see also Fischer, 1943). Such findings also explain the negative results described in recent years by Chor et al. (1939) and Molander et al. (1941.) Moreover, these authors and others (Hartmann and Blatz, 1920) combined inadequate technique with skeletal immobilization of the paralysed limbs, a method which in itself can produce atrophy (Solandt, 1942) or retard the recovery of 
muscle volume and strength after re-innervation (Hines, 1942).

The experiments described here reveal the great importance of activity as the leading factor in preventing muscular atrophy. Although the present experiments (see case 934) do not prove that inactivity is the only cause of atrophy after denervation, they show clearly that the impulses which are responsible for the normal muscular activity and which are lost after denervation can be effectively replaced by galvanic exercise.

Activity appears to be the important factor for the healthy "trophic state" of a muscle. Recently Hines et al. (1943) found in denervated muscles a greater creatine content on the side which was treated with induction shocks. It appears that galvanic exercise produces better metabolic conditions for the denervated muscle. How these better metabolic conditions are achieved is still unknown, but the effect of exercise on the circulation may possibly be responsible. This is suggested by the development of vasodilatation and increase of volume observed after onset of treatment. In fact muscle activity increases the circulation, and the volume of blood in an active muscle may be 3-5 times that found in an inactive one (see Mann, 1936). It is notable that electrotherapy has been found to be less effective in human subjects in whom there has been damage to the vessels in addition to the nerve lesion, either at the time of injury or as the result of later plaster or splintage (Guttmann L., 1942).

It might be thought that the increased metabolism, which prevents atrophy in denervated muscles, is due mainly or entirely to the ionic (cataphoretic or electro osmotic) or thermal effects of the current, but methods such as heat, diathermy, short waves and uninterrupted galvanic current have so far proved definitely inferior to interrupted galvanic current in preventing atrophy of denervated muscles. Moreover, the experiments described here show that interrupted galvanic current failed to prevent atrophy if it produced only feeble contractions, while vigorous contractions produced by daily galvanic exercise go far towards replacing the reflex and voluntary impulses which normally maintain the action of the muscle and its normal metabolic conditions.

\section{Summary}

Daily application of galvanic exercise with a current strength sufficient to elicit vigorous contractions of the muscles was found to delay and diminish atrophy in denervated and re-innervated rabbit muscle. The most satisfactory results were obtained with a daily exercise of 20-30 minutes duration. The effect was greater the earlier the treatment was started following denervation.

Treated muscles showed larger muscle fibres and less fibrosis than untreated ones.

After a maximal treatment (1 hour daily), beginning immediately after denervation, the muscles lost only 17 per cent. in weight in 60 days, compared with a loss of 59 per cent. in untreated muscles.

No attempt was made to avoid fatiguing of the stimulated muscles during the exercise and this did not prevent the beneficial end effect.

The main effect of the treatment appeared during the period of denervation but a difference was still demonstrable 4 months after interruption of the galvanic exercise. The effect of treatment is therefore not masked by the normal process of muscle recovery after re-innervation.

No certain effect of galvanic exercise was found on the time of onset of motor recovery, but the degree of motor recovery was higher in the treated muscles.

The authors are very indebted to Mr. J. Z. Young for his help and advice throughout the whole course of this work and for revision of the paper. The expenses of this investigation were defrayed by a grant from the Rockefeller Foundation to the Department of Zoology. The authors also wish to acknowledge a grant by the Nuffield Committee for the Advancement of Medicine.

\section{REFERENCES}

Chor, H., Cleveland, D., Davenport, H. A., Dolcart, R. E., and Beard, G. (1939). J. Amer. med. Assoc., 113, 1029.

Eccles (1941). Med. J. Austr., 537.

Fischer, E. (1939). Amer. J. Physiol., 127, 605.

- (1943). Ann. Rev. Physiol., 5, 133.

Gutmann, E. (1942). J. Neurol. Psychiat., 4, 81.

Guttmann, L. (1942). Proc. roy. Soc. Med., 35, 305.

Gutmann, E., and Guttmann, L. (1942). Lancet, Feb. 7, 169.

Hartmann, F. A., and Blatz, W. E. (1920). J. Physiol., 53, 290.

Hines, H. M. (1942). J. Amer. med. Assoc., 120, 515.

- Thompson, J. D., and Lazere, B. (1943). Arch. phys. Ther., 24, 69.

Langley, J. N., and Kato, T. (1915). J. Physiol., 49, 432.

Mann, L. (1936). Handbuch der Neurologie, 8, 497 (T. Springer, Berlin).

Molander, C. O., Steinitz, F. S., and Asher, R. (1941). Arch. phys. Ther., 21, 154.

Newman, M. K., Berris, J. M., and Bohn, N. (1940). Ibid, 21, 270.

Solandt, D. Y. (1942). J. Amer. med. Assoc., 120, 511. and Magladery, J. W. (1940). Brain, 63, 255. De Lury, D. B., and Hunter, T. (1943). Arch. Neurol. Psychiat., 50, 802.

Tower, S. S. (1937). J. comp. Neurol., 67, 241.

(1939). Arch. Neurol. Psychiat., 42, 219.

Weddell, G., Feinstein, B., and Pattle, R. E. (1943). Lancet, Feb. 20, 236.

Young, J. Z., and Medawar, P. M. (1940). Lancet, 2, 126. 